
D:\Nsurg \Vol. 24, No. 1, Jan. - Mar., 2020\Nsurg-3.Doc
Fig. A-F Color
(A)
P. $40-50$
II

ORIGINAL ARTICLE

\title{
Transaxillary Transthoracic Approach to Upper Dorsal Spine Lesions: An Anatomical Corridor with Muscle Preservation
}

\author{
FAHMIDA ARAB MALLAH ${ }^{1}$, ABDUL RAZZAQUE MARI ${ }^{1}$, MUZAMIL DILBER ${ }^{1}$ \\ SHAMS RAZA BROHI ${ }^{1}$, SYED AAMIR SHAH ${ }^{2}$, MUHAMMAD ALI JAMALI ${ }^{1}$ \\ HAMID AKBAR SHAIKH ${ }^{1}$ \\ ${ }^{1}$ Peoples University of Medical and Health Sciences for Women, Shaheed Benazirabad \\ ${ }^{2}$ Pakistan Institute of Medical Sciences, SZABMU, Islamabad, Pakistan
}

DOI: 10.36552/pjns.v24i1.412

\begin{abstract}
Objective: Conventional methods for anterior upper dorsal spine are not devoid of intra-operative complications due to anatomical constraints, a major blood vessel and vital organs. We analyzed the details of Trans-axillary approach without muscle cutting in tuberculosis, tumor, and traumatic lesions of T2 to T6 and upper limb causalgia.
\end{abstract}

Materials and Methods: A prospective quasi-experimental study was conducted for 3 years included 30 patients presented with dorsal myelopathy due to D2 to D6 vertebral body involvement. Right and left sided approaches were utilized. Medical Research Council grading was used to assess neurological status.

Results: Mean age was $32 \pm 15$ years, which included male $18.60 \%$ and female $12.40 \%$. T4 vertebrae were commonly involved. Others were T5, T3 and T6 respectively. The majority of lesions were tuberculosis of the spine $(n=14)$, tumor $(n=8)$, trauma $(n=5)$ and causalgia of upper limb $(n=3)$. No intra-operative complications occurred, estimated blood was 80-100 ml and operative time was 120-160 minutes. Postoperative complications included pneumonia $(n=1)$, superficial wound infection $(n=3)$, death $(n=1)$. Serial follow up was for 2 years, Patients were discharged with improved neurological status and causalgia patients got immediate post-operative relief.

Conclusions: Transaxillary approach is a unique anatomical corridor which is safe, feasible with promising results. It provides optimal decompression, reconstruction with better fixation and alignment in various pathologies of upper dorsal spine.

Keywords: Transaxillary, transthoracic, upper thoracic, muscle preservation technique, spine, causalgia.

\section{INTRODUCTION}

Upper dorsal spine (thoracic vertebra $\mathrm{T} 1$ to $\mathrm{T} 6$ ) possesses unique anatomical and biomechanical properties such as anterior aspect of the vertebral bodies is smaller than posterior aspect which contributes to physiological kyphosis. Due to this anterior axis rotation compression fracture is most common. ${ }^{1,2}$ This region joins two different anatomical spaces i.e. cervical and thoracic cavity. Cervical lordotic mobile segment unites with the thoracic kyphotic fixed segment. Vertebral bodies, ribs and sternum provide segmental biomechanical stability 2-3 times that of thoracolumbar junction. Costovertebral joints form a bony cylindrical shell that provides stability and rigidity, so greater force is required to cause significant fracture. ${ }^{3}$

Due to narrow gap between Spinal canal and cord along with tenuous blood supply, dorsal spine lesions mostly cause complete spinal cord injury and present with myelopathy (spastic paraplegia) often may present with Costobrachalgia. ${ }^{4}$

Dorsal spine fractures accounts about $17-23 \%$ of 
all spinal fractures and $22 \%$ of traumatic fractures occurring between D1 and D4 vertebrae. ${ }^{5}$ Whereas $40 \%$ of metastatic lesions and about $5 \%$ of disc herniation and tuberculous lesions occurring at this level. $^{6}$

It creates surgical challenges for surgeon approaching upper thoracic spine lesions because narrow thoracic outlet, vital contents of mediastinum the heart, lung and neurovascular structures along with limitation by the shoulder and scapular muscles. ${ }^{7}$

A variety of surgical approaches are tailored depending upon feasibly on the surgeon and location of lesion, and most common are supraclavicular, transmanubrium transthoracic and lateral para scapular extra pleural approaches. ${ }^{8}$

We describe our experience with the trans-axillary transthoracic an anatomical approach in a variety of lesions involving the upper dorsal spine. This approach is relatively safe and feasible that provides optimal and excellent decompression of upper dorsal spine vertebrae and thecal sac, along with better reconstruction, instrumentation and alignment of the dorsal spine. It also optimizes neurological recovery and immediate postoperative relief from causalgia secondary to firearm injury.

\section{MATERIALS AND METHODS}

\section{Study Design}

Prospective descriptive study. This descriptive study was conducted in the neurosurgery department of the Peoples' University of medical and health sciences for women Nawabshah over a period of 3 years from July 2016 to June 2019.

\section{Inclusion Criteria}

All patients presented in emergency, outpatient department or directly referred to the ward with spastic paraplegia were assessed clinically and on radiology to have the sign and symptoms of upper dorsal spine lesions. Upper limb causalgia secondary to firearm injury was another indication for admission. Average time to diagnosis was 12 months (3-24 months). Neurological function was assessed by MRC (medical and research council) grading. Those patients willing for surgery, having average built, MRC grade 1 or above and variety of lesions involving D2 to D6 vertebrae and causing significant spinal cord were included in the study.

\section{Exclusion Criteria}

Patients having MRC grade 0, obese patients with hypertrophic pectorals or latissimus dorsi muscle, lesion above D1 were excluded from the study.

\section{Data Collection}

All data was entered in specified performa. Plain Xrays, computed tomographic scan and Magnetic resonance imaging with and without contrast were done in all patients. Procedure related information was clearly enrolled in proforma. All photographs have been captured with the Consent of patient/attendant

\section{Transaxillary Transthoracic Operative Technique:}

After the endotracheal general anesthesia patient was positioned on operative table both right and left sided approaches were utilized. Here, we describe left lateral decubitus position, arm elevated above the head and carefully protected wrist and forearm, about $5-6 \mathrm{~cm}$ of incision is marked along the posterior border of latissimus dorsi that runs are parallel to the long thoracic nerve (Figure A).

Skin and subcutaneous tissue dissected along the line of incision carefully to avoid damaging long thoracic nerve, which is mobilized laterally, then dissection is carried out without muscle splitting in between $1^{\text {st }}$ and $2^{\text {nd }}$ digitation of serratus anterior muscle, $3^{\text {rd }}$ rib is the principle site for gaining access to upper dorsal spine, a sub periosteal dissection of intercostal muscle is done while protecting the inferior neurovascular bundle, about $5-6 \mathrm{~cm}$ of rib is removed (Figure B). The pleura is incised carefully; Devers or chest retractor is placed then lung is retracted away from midline with malleable or eggbeater retractor to expose the spine through parietal pleura (Figure C). In case of tumor or caries spine we always found a localized lump or bulge at the site of the lesion where as in traumatic fracture paravertebral muscle and tissues are most of the time bruised which always guide us to the pathological site.

Parietal pleura over anterior spine is incised and the flap is reflected away, pathological tissue that causing compression over spinal cord is removed with the help of roengers, chisel, and curators, until the posterior longitudinal ligament or dura is visible. Rib head resection and discectomy is performed one level above and below the level of lesion which helps in early identification of the dura. Rectangular corpectomy is performed which creates excellent graft 


\section{Pictures have been Captured with the Consent of Patient/Attendant}

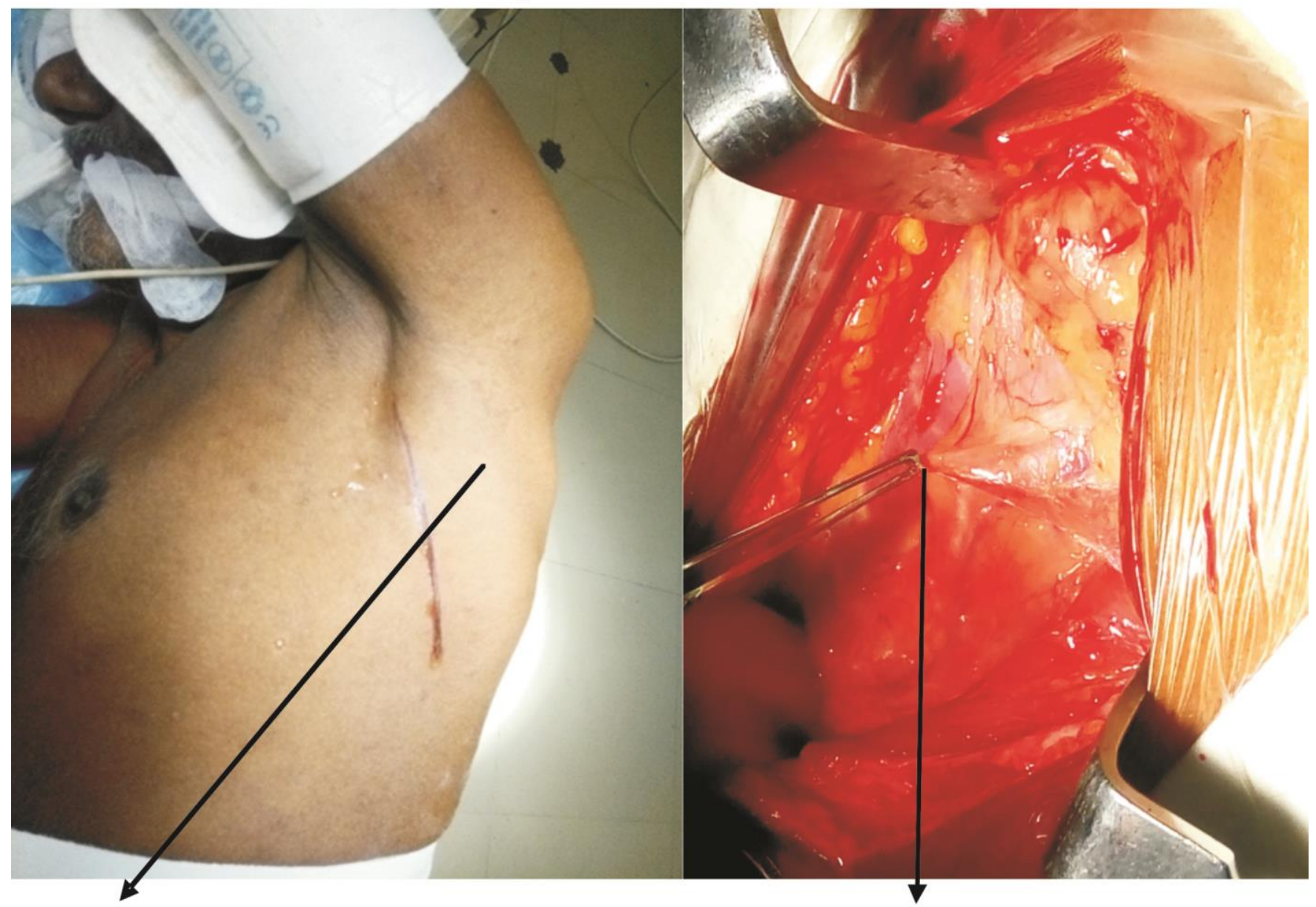

A/a: Incision along anterior; Border of Latissimus Dorsi Image.

A/b: Long thoracic Nerve Exposed Image.

Fig. A:

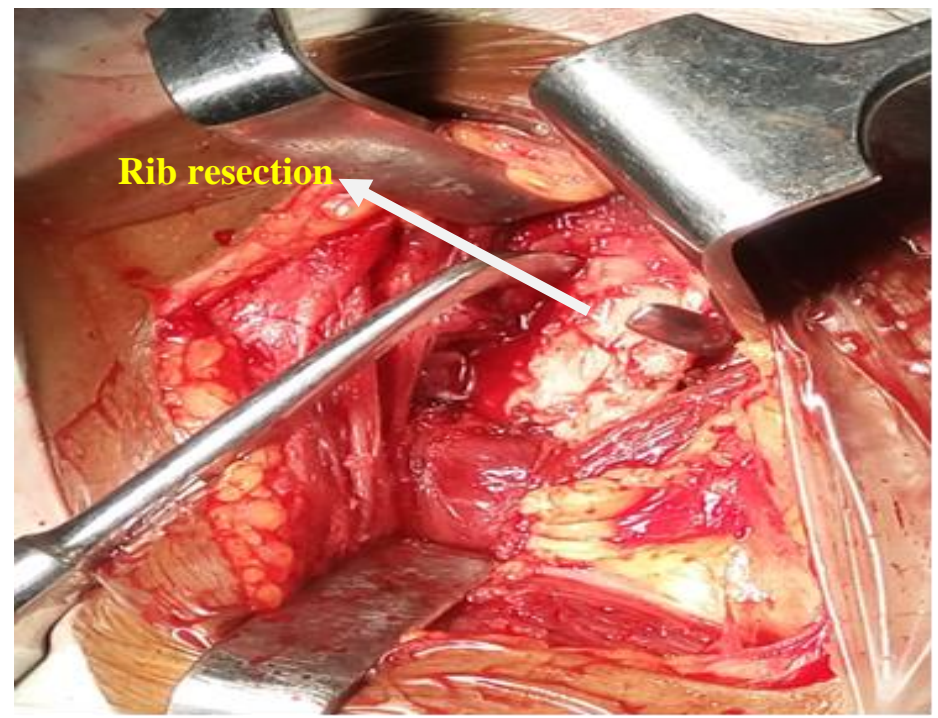

Figure B: Intraoperative View of $3^{\text {rd }}$ Rib Resection. 

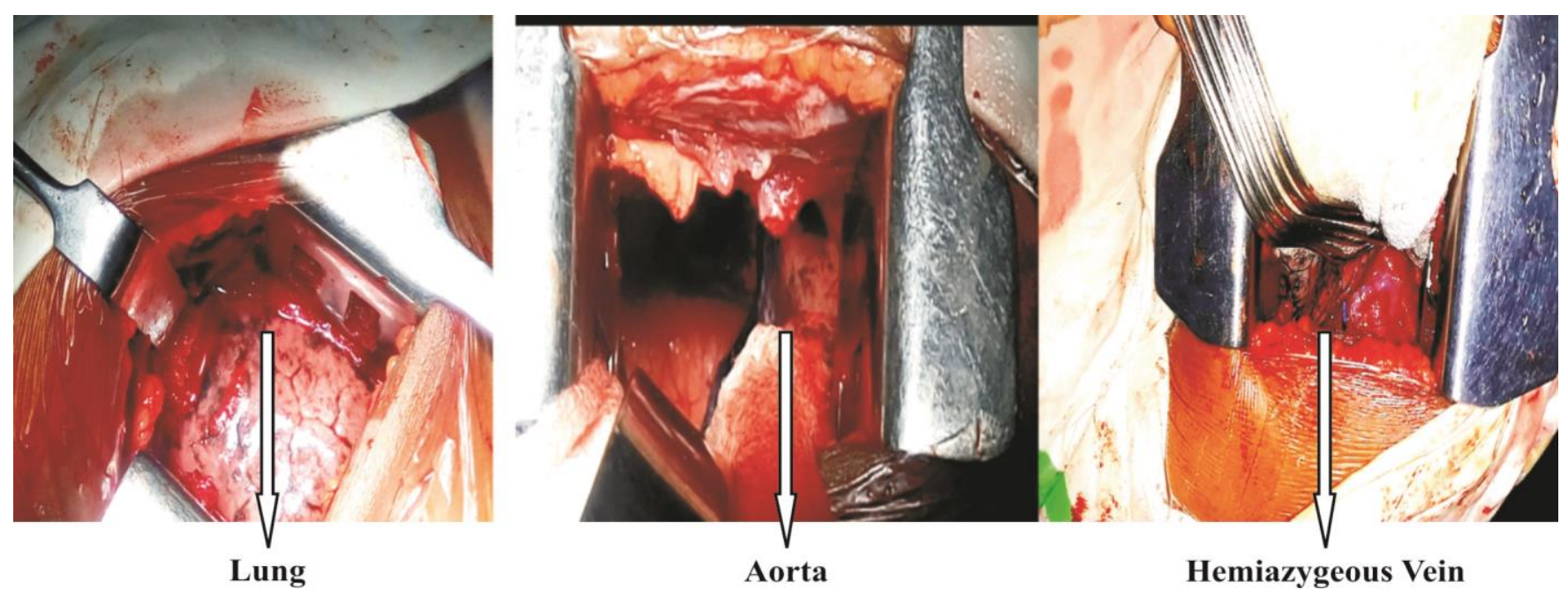

Fig. C: Intraoperative stepwise exposure of ipsilateral lung, Aorta in Left and Hemiazygeous vein on Right side approach.

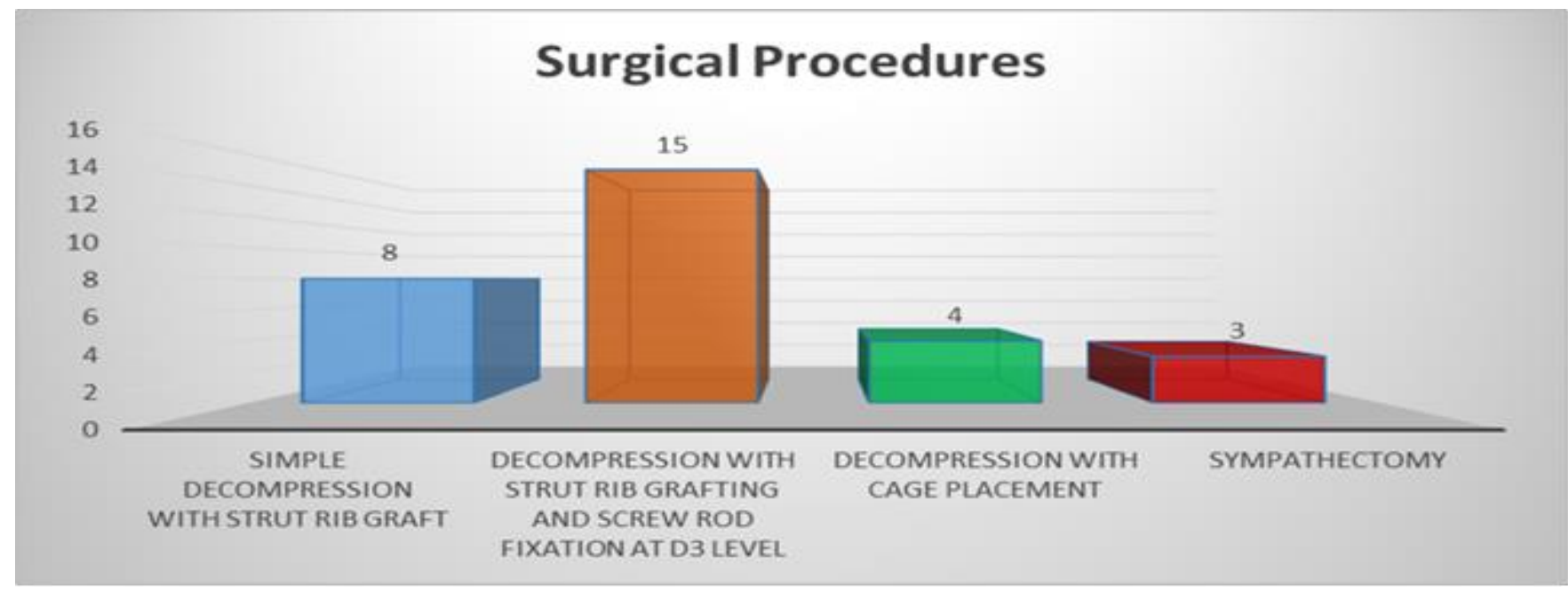

Fig. D: Various Surgical Interventions.

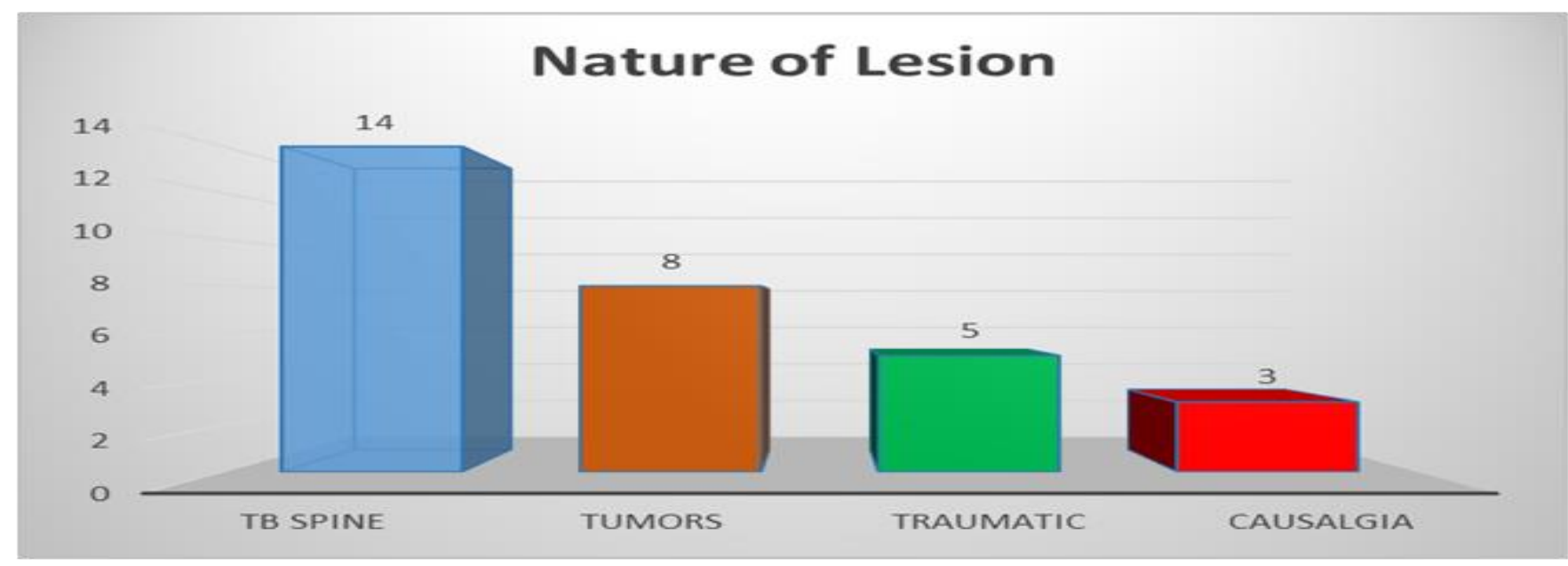

Fig. E: Different Nature of Lesions. 
recipient site. Variety of reconstruction technique from simple decompression strut rib grafting, screw rod fixation one level above and below the involved vertebrae to cage placement were tailored depending on the quality of bone and involved vertebrae along with pathological lesion and economic condition of patient detailed (Figure D).

Segmental vessels at the waist of the vertebral bodies are properly diathermies with bipolar forceps and divided, it is the point where screw fixation is done. Proper purchase of screw into vertebral body is confirmed with intra operative lateral X -ray films.

For sympathectomy in case of Causalgia, sympathetic chain is identified as it passes over the neck of $2^{\text {nd }}$ rib, with the help of diathermy forceps overlying parietal pleura is opened and the D2and D3 sympathetic chain is divided under direct vision.

Finally, the cavity is washed with normal saline, hemostasis is secured, when the lung is fully reinflated, upper and lower ribs are pierced with towel clips, silk suture is passed and with the help of little force ribs are re approximated. Surgical wound is closed without putting chest tube and antiseptic dressing is applied.

After recovery from the anesthesia patient is kept in the high dependency unit for 48 hours under cover of intravenous antibiotics and Non-steroidal antiinflammatory analgesics. First postoperative X-ray chest is done after 12 hours to rule out hemothorax or pneumothorax.

\section{RESULTS}

\section{Sex Incidence}

In our study out of 30 patients, 18 were male and 12 were female, with male to female ratio 3:2.

\section{Age Incidence}

Mean age at presentation was $40 \pm 20$. Eight patients having comorbid pulmonary tuberculosis, 5 patients having hypertension, 4 with diabetes and 2 patients present with diabetes with hypertension, which was controlled with medication at the time of admission. The most common level of vertebra involved were T4 $(\mathrm{n}=14)$, T5 in $(\mathrm{n}=8)$ T3 in $(\mathrm{n}=6)$ and T6 in 2 patients. We further classified it according to the nature of the lesion and the most common lesion was tuberculosis of the spine in 14 patients further detail (Figure E).

In our neurosurgical setup we are mostly familiar with left side to approach anterior spine so we approached from left side in 24 patients and in 6 patient right side was also utilized. Advantage of right side approach is that even you palpate otherwise of vertebral body and can feel screw head if it's too long. Average operative time was $120-160$ minutes and average intraoperative blood loss was $80-100 \mathrm{ml}$, no intraoperative complications like cerebrospinal fluid leaks, or injury to the aorta, lung or spinal cord and nerve roots were encountered.

Depending on the quality of bone, and alignment of the spine, age and economic condition of patients we tailored different surgical procedures.

Patients with advance age and disease, we performed a simple decompression of the cord in $(\mathrm{n}=8)$, decompression with strut rib grafting and screw rod fixation $(n=15)$ was done in young patients having poor spine alignment.

Economical affordable patients whether young or old decompression with cage placement was performed in $(n=4)$ patients.

All 3 patients who presented with upper limb causalgia secondary to firearm injury got immediate postoperative relief from pain during follow up period patient has good pain controlled along with GABA inhibiting drugs. None of patient developed Horner syndrome, one patient developed compensatory hyperhidrosis, which he mixed with warm local area climate.

On $10^{\text {th }}$ postoperative day three patients developed a superficial wound infection, which was managed successfully with empirical intravenous antibiotics and daily antiseptic dressing. One patient experienced hospital acquired pneumonia, which was also managed with intravenous antibiotics. A middle age patient with diabetes and hypertension died on the $3^{\text {rd }}$ postoperative day due to myocardial infarction, which was not directly related to operative procedures. All patients had good postoperative pain controlled with intravenous non-steroidal anti-inflammatory drugs (Ketorolac/Toradol which was given 12 hourly for first 24 hours, then shifted to oral medication for next 7 days.

Regular follow up was carried out in the outpatient department for 2 years. $1^{\text {st }}$ follow up after 14 days $2^{\text {nd }}$ after 30 days to 3 months to after six months then after 12 months finally after 2 years (Table 1 ).

A patient who fell to follow-up was contacted on mobile and their neurological status was inquired and recorded.

In our study, all patients improved neurologically 


\section{Neurological Status}

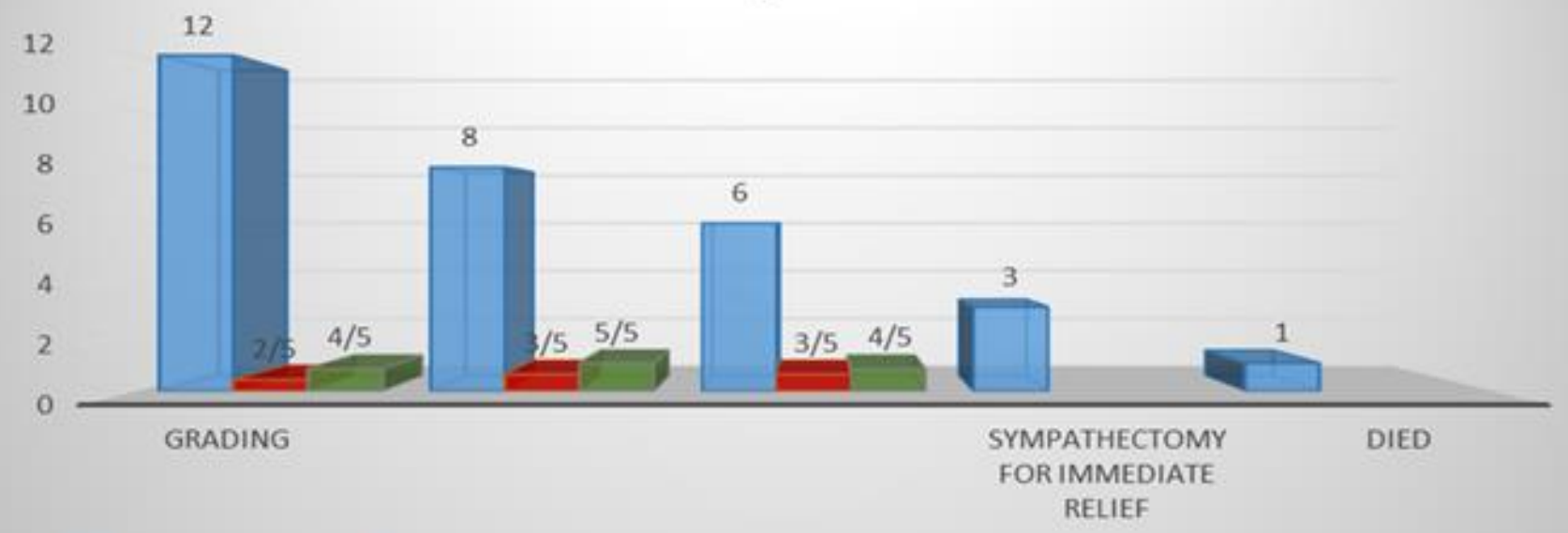

$\square$ Number of patients $\mathbf{m}$ Pre-Operative MRC Grading of lower limbs $\square$ Post-Operative MRC Grading lower limbs

Fig. F: Initial Neurological Status and Progress.

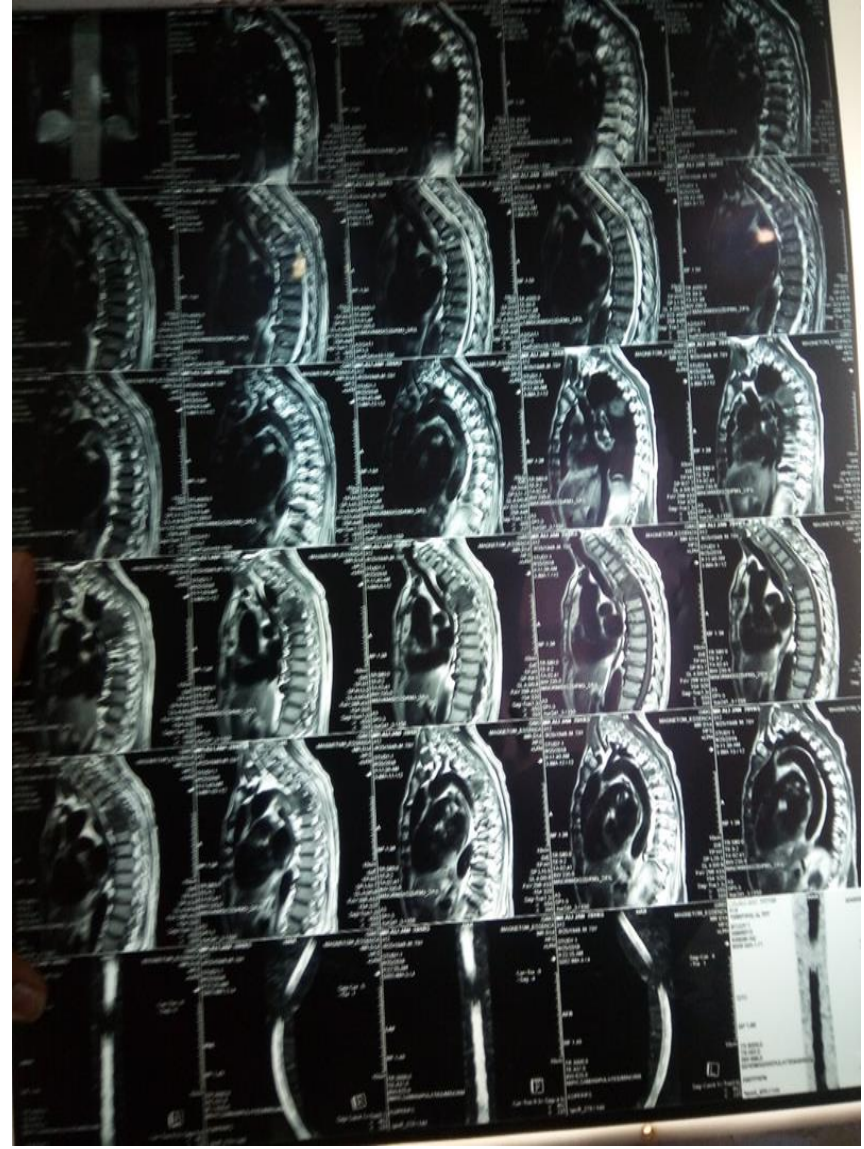

Pre-Operative MRI Sagittal Image G/a showing severe cord compression at D5.

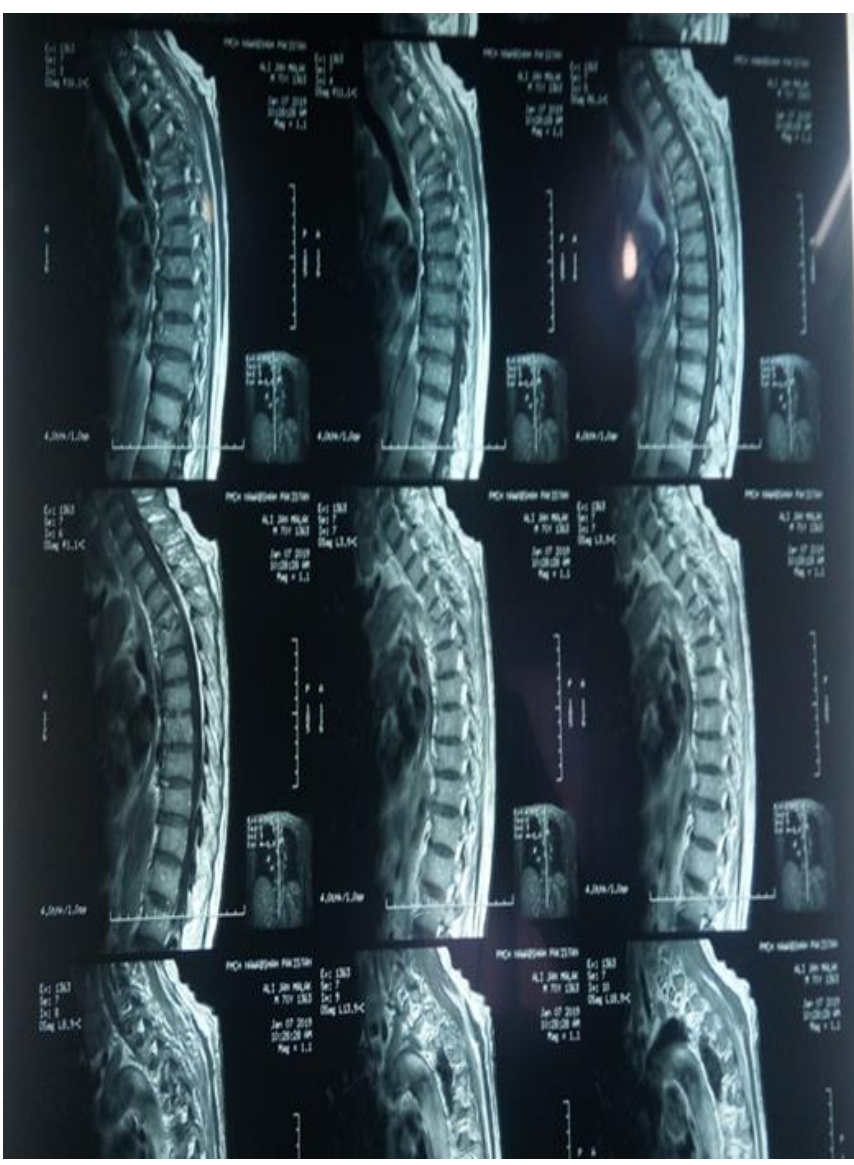

Post-Operative MRI Sagittal Image G/b Showing complete cord decompression at D5 level. 
Transaxillary Transthoracic Approach to Upper Dorsal Spine Lesions: An Anatomical Corridor with Muscle

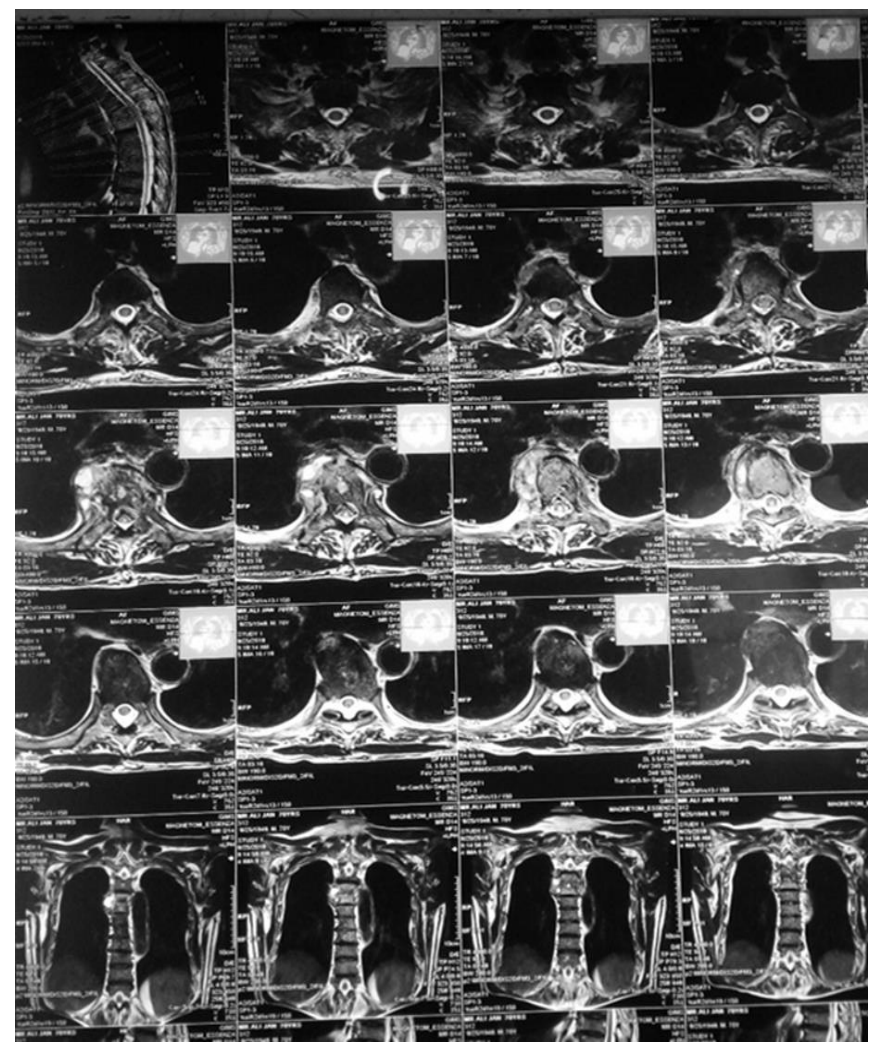

Pre-Operative MRI Axial Image G/c severe cord compression on right side

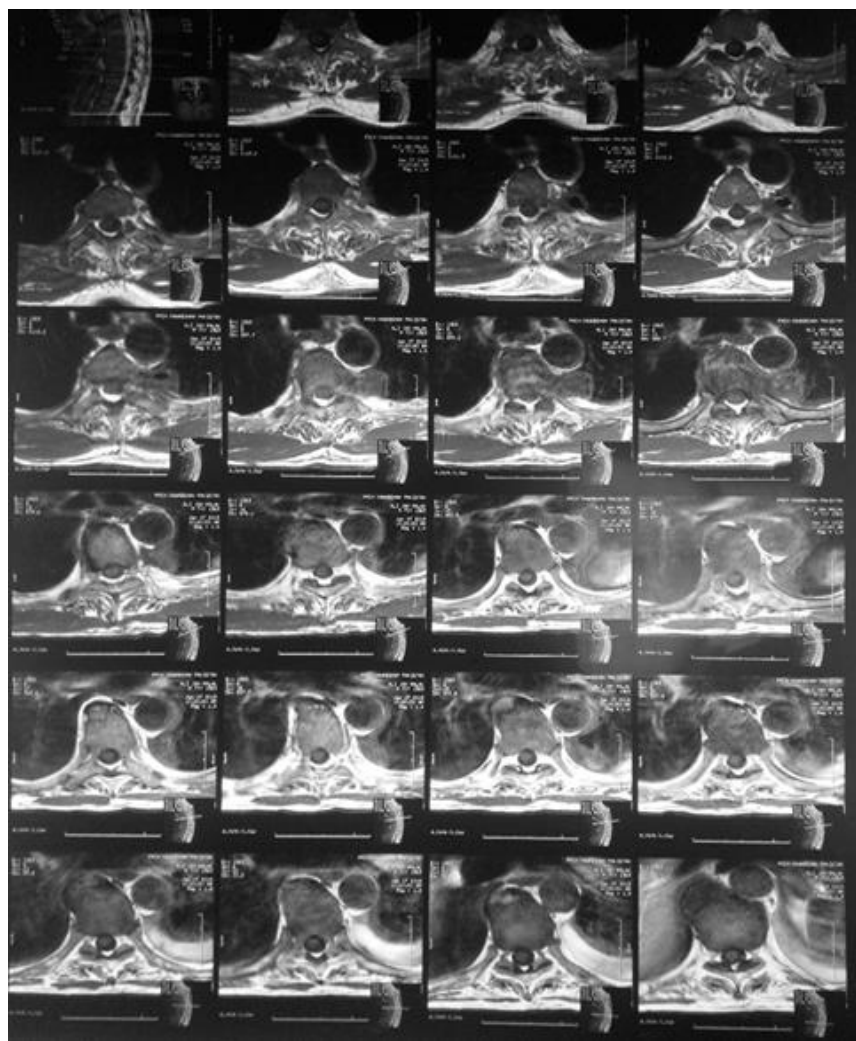

Post-Operative MRI Axial Image G/d showing decompression on right side

Fig. G:

Table 1: Serial Follow-up and Neurological Status.

\begin{tabular}{|c|c|c|c|c|c|c|c|c|}
\hline 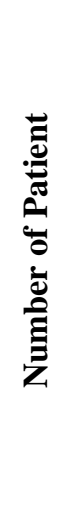 & 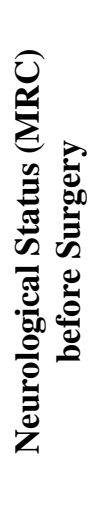 & 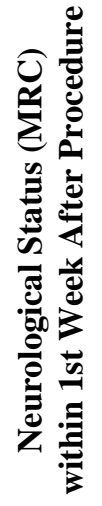 & 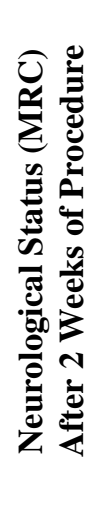 & 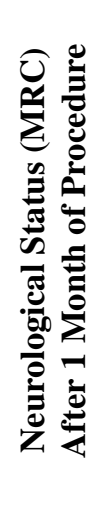 & 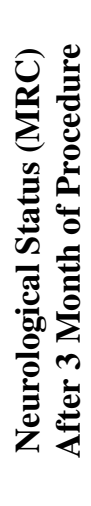 & 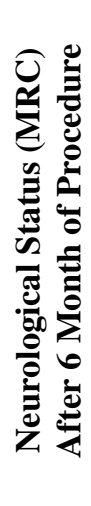 & 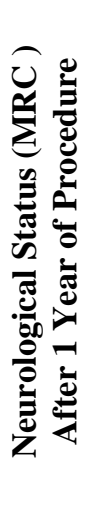 & 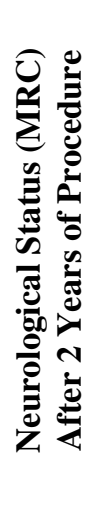 \\
\hline 12 & $2 / 5$ & $3 / 4$ & $4 / 5$ & $5 / 5$ & $5 / 5$ & $5 / 5$ & $5 / 5$ & $5 / 5$ \\
\hline 8 & $3 / 5$ & $3 / 5$ & $4 / 5$ & $4 / 5$ & $5 / 5$ & $5 / 5$ & $5 / 5$ & $5 / 5$ \\
\hline 6 & $3 / 5$ & $3 / 5$ & $3 / 5$ & $3 / 5$ & $4 / 5$ & $4 / 5$ & $5 / 5$ & $5 / 5$ \\
\hline
\end{tabular}


Table 2: Advantage and Disadvantages of Various Approaches to Upper Dorsal Spine.

\begin{tabular}{|c|c|c|c|c|c|c|}
\hline & Our Study & $\begin{array}{l}\text { Traditional } \\
\text { Transaxillary }\end{array}$ & $\begin{array}{l}\text { Trans } \\
\text { Manubrial } \\
\text { Supraclavicular }\end{array}$ & $\begin{array}{l}\text { Trans- } \\
\text { Sternal }\end{array}$ & Transthoracic & $\begin{array}{l}\text { Lateral } \\
\text { Prascapular } \\
\text { Extrapleural }\end{array}$ \\
\hline Incision & $\begin{array}{l}\text { Along anterior } \\
\text { border of } \\
\text { latissimus dorsi }\end{array}$ & $\begin{array}{l}\text { Transverse } \\
\text { axillary skin } \\
\text { crease }\end{array}$ & $\begin{array}{l}\text { Vertical along } \\
\text { the ant; border } \\
\text { of SCM muscle } \\
\text { to mid of } \\
\text { manubrium }\end{array}$ & $\begin{array}{l}\text { Vertical } \\
\text { midline of } \\
\text { sternal } \\
\text { body }\end{array}$ & Oblique & Hockey stick \\
\hline Level assess & T1-T7 & C7-T4 & C7-T4 & T1-T4 & $\mathrm{T} 2$ and below & C2-D7 \\
\hline $\begin{array}{l}\text { Neurovascular } \\
\text { injury }\end{array}$ & Nil & Possible & Usually & Usually & Not common & $\begin{array}{l}\text { Rami } \\
\text { communicates } \\
\text { of C8-T1 } \\
\text { transected }\end{array}$ \\
\hline Mortality & Nil & Not common & High & High & Low & Low \\
\hline Thromboembolism & Nil & Not common & Usually & Usually & Not common & Not common \\
\hline Osseous injury & $\begin{array}{l}3-4 \mathrm{~cm} \text { of } \mathrm{Rib} \\
\text { resected }\end{array}$ & $\begin{array}{l}4-5 \mathrm{~cm} \text { of rib } \\
\text { resection }\end{array}$ & $\begin{array}{l}\text { Manubrio } \\
\text { Clavicular non } \\
\text { union }\end{array}$ & $\begin{array}{l}\text { Manubrio } \\
\text { Sterno } \\
\text { clavicular } \\
\text { non union }\end{array}$ & Rib resection & $\begin{array}{l}\text { Dorsal rib } \\
\text { resection }\end{array}$ \\
\hline Disadvantages & $\begin{array}{l}\text { Needs long } \\
\text { instruments } \\
\text { difficult } \\
\text { instrumentation } \\
\text { for D1 and D2 }\end{array}$ & $\begin{array}{l}\text { Brachial } \\
\text { plexus injury, } \\
\text { inability to } \\
\text { reach C7-T1, } \\
\text { limited lateral } \\
\text { assess to } \\
\text { anterior VB }\end{array}$ & $\begin{array}{l}\text { Severe pain, } \\
\text { injury to lateral } \\
\text { thoracic artery, } \\
\text { vascular } \\
\text { embolism } \\
\text { (heparin } \\
\text { needed). Limited } \\
\text { access to T1-T2 }\end{array}$ & $\begin{array}{l}\text { Severe } \\
\text { pain, } \\
\text { injury to } \\
\text { lateral } \\
\text { thoracic } \\
\text { artery, } \\
\text { vascular } \\
\text { embolism } \\
\text { (heparin } \\
\text { needed). } \\
\text { Right } \\
\text { Recurrent } \\
\text { laryngeal } \\
\text { nerve } \\
\text { injury }\end{array}$ & $\begin{array}{l}4-5 \mathrm{~cm} \text { of rib } \\
\text { resection, C7 } \\
\text { T1 not } \\
\text { accessed. }\end{array}$ & $\begin{array}{l}\text { Reflection of } \\
\text { parascapular } \\
\text { muscle } \\
\text {.limited } \\
\text { access to ant; } \\
\text { pathology }\end{array}$ \\
\hline
\end{tabular}

and rapid recovery was noticed almost in all patients of tuberculosis of the spine $(n=14)$ irrespective of cord compression and neurological status, which was noticed even after 24 hours of surgery.

Out of 30 patients, 12 patients presented with MRC grade $2 / 5$, improved on $5^{\text {th }}$ postoperative day to $4 / 5$, eight patients with MRC grade 3/5 improved to $5 / 5$ after 2 weeks and 6 patients with MRC grade $3 / 5$ improved to $4 / 5$ after 6 months (Figure F).

Serial X-rays dorsal spine, anterio-posterior and lateral view if needed CT scan and MRI (when no implant) was done on follow up in each case to confirm the cord decompression and instrument stability (Figure G). No significant change in spine alignment or instrument failure or migration was noticed.

\section{DISCUSSION}

Management of upper dorsal spine lesions to approach anterior spinal pathology is to be a continuous challenging task for surgeons. Both ventral and dorsal approaches have been employed to access the upper dorsal spine lesions. Ventral approaches include anterior cervicothoracic and transthoracic, lower cervical and upper 3 dorsal vertebrae can be visualized 
by low anterior cervical incision along with median sternotomy or manubriotomy with or without removal of the clavicle. However, Cervicothoracic has limited access to $\mathrm{C} 6$ to $\mathrm{T} 2$ and median sternotomy or manubriotomy provides very limited access beyond the caudal aspect of T3. ${ }^{9,10}$ Moreover, these approaches need to mobilized recurrent laryngeal nerve, trachea, esophagus, great vessels and thoracic duct with increased risk of injury and increased morbidity and mortality. High thoracotomy in lateral decubitus position is used to access dorsal spine below T3. This approach requires transection of the trapezius, rhomboids and latissimus dorsi along with a retraction of the scapula that causes profound pain and limitation of shoulder movement. ${ }^{11}$ Sometimes, these approaches required circumferential techniques or an additional posterior staged procedure which is an additional factor for increased morbidity. ${ }^{12}$

Each of these approaches has its own prognosis and consequences for detail Table 2. Hodgson et al. were the first to described thoracotomy for anterior spinal pathology in Potts' disease of spine. ${ }^{13,14}$ Since then anterior thoracotomy was used for management of dorsal spine tumors, both primary and secondary, fracture dislocation, disc herniation and severe kyphotic deformity with spinal cord compression. ${ }^{15,16}$

Professor R.H Goetz from South Africa first time utilized transaxillary space in 1949 and did the demonstration in England, but he didn't publish it. After that Atkins of England had described the procedure. In 1962, Ross introduced trans axillary approach for first rib excision for thoracic outlet syndrome, since then trans axillary approach was popularized in general surgeons for breast surgery, ENT surgeons for thyroidectomy, vascular surgeons for vascular surgery and neurosurgeons utilized it most commonly for TOS also for sympathectomy procedures. ${ }^{17,18}$

Our surgical technique trans axillary and transthoracic approach is the modification of two techniques the traditional trans axillary and transthoracic approach, in traditional trans axillary approach transverse $7-9 \mathrm{~cm}$ of incision is given at the root at axillary fold where as in our approach its 6-7 oblique incision along anterior border of the latissimus dorsi. In transthoracic, pathology was accessed through 4 or 5 ribs, where as we entered from $3^{\text {rd }}$ rib. Traditional trans axillary most commonly used for thoracic out let syndrome for both neurogenic and vascular, brachial plexus, with increased risk of injury to axillary vessels, brachial plexus, violation of axillary fat, muscles, injury to long thoracic and $2^{\text {nd }}$ intercosto brachial nerve, pectoral major muscle also limited lateral access ventral vertebral. ${ }^{19,20}$ In contrast to that, our technique is extremely safe we approach the anterior vertebral body and theca and its lesions and sympathetic chain, without causing harm to lateral thoracic nerve, major muscle like pectorals, latissimus dorsi and serratus anterior muscle or Stellate ganglion. It optimized the maximum exposure and decompression of anterior vertebral body and spinal theca. Transaxillary technique provides proper alignment of spine and appropriate instrumentation from D2 to D6 without mobilization of great vessels. One drawback of this approach is that you need long instruments and intermittent retraction of lungs, but we didn't encounter any inadvertent injury to lung, dura or cord, none of our patient's neurological function deteriorates postoperatively.

In 2016, Christian brogan et al. did a study on mini trans sternal approach for upper dorsal spine lesion, where average operative time wa150 - 280 minutes, $75 \%$ neurological improvement, $22 \%$ remained same, $0 \%$ mortality no CSF leak or dural tear was encountered in their study 2 patient had got severe postoperative pain, one patient got pneumonia and one patient got postoperative hematoma. ${ }^{21}$

Another study conducted on manubriotomy for upper thoracic spine by Asdrubal Falavigna et al, in which they mentioned the average operative time was $3.7 \mathrm{hrs}$, the average blood loss of $280 \pm 122$ minutes along with manubriotomy they performed staged posterior instrumentation also. Patients also experienced severe postoperative pain, spinal instability and hematoma formation. ${ }^{22}$

In comparison to both above mentioned study, our technique is profoundly safe, we encountered $80-100$ $\mathrm{ml}$ blood loss, average operative time was $120-160$ minutes, more than $90 \%$ neurological improvement, we experienced $0 \%$ mortality related to procedure, none of our patient got a CSF leak or dural tear. There was mild to moderate postoperative pain which was successfully managed with NSAID.

Walter et al. done a study on the transaxillary approach for upper limb sympathectomy on 11 patients, out of 11 patients 4 got transient pleural effusion, three patients experienced pneumothorax, one patient got winging of scapula. ${ }^{23}$ In our study, none of our patient developed pleural effusion or hemothorax or pneumothorax or winging of scapula.

Therefore, transaxillary approach should be considered for upper dorsal spine surgical approaches, 
especially for lesions involving anterior high vertebral body with cord compression or in the patients that needs sympathectomy along with proper and safe decompression without violation of major muscles, neurovascular structures, brachial plexus.

\section{CONCLUSION AND RECOMMENDATION}

Upper dorsal spine is often considered as a "no mans' land."

Traditional approaches like anterior transmanubrium, trans sternal and posterior subscapular approach which employ to upper dorsal spine lesions are not devoid of major complications to neurovascular, vital organs and musculoskeletal system.

Transaxillary is a unique anatomical corridor that is safe, feasible with promising results and good prognosis in patients with upper thoracic spine tuberculous, tumor and traumatic lesions along with causalgia secondary to firearm injury.

This approach suitable for direct access to upper dorsal theca also provides optimal decompression, reconstruction along with better fixation and alignment in various pathologies of upper dorsal spine.

Further work should be done perioperative use of endoscopic and microscopic technique; it would be quite safe to use spinal cord monitoring during decompression of spinal cord lesions.

\section{REFERENCES}

1. Lesoin F, Autricque A, Villette L, Jomin M. [Anterior approach to the upper dorsal spine (D1 to D4) by sternobiclavicular monoblock mobilization]. Neurochirurgie 1998; 32: 269-271.

2. Dighe MP, Balasubramaniam S, Nadkarni TD. Transthoracic approach for ventrally situated paraspinal extradural hydatid cyst of the dorsal spine. J Craniovertebr Junction Spine, 2018; 9: 271-273.

3. Freixinet J, Hussein M, Mhaidli H, Rodriguez Suarez P, Robaina F, Rodriguez de Castro F. [Transthoracic approach to the spinal column]. Arch Bronconeumol, 1998; 34: 492-495.

4. Grootboom MJ, Govender S.Acute injuries of the upper dorsal spine. Injury, 1993; 24: 389-392.

5. Hernigou P, Kooli M, Fevrier MJ, Goutallier D. [Anterior approach to the high thoracic spine by the subscapular route]. Rev Chir Orthop Reparatrice Appar Mot. 1991; 77: 353-358.

6. Lam FC, Groff MW. An anterior approach to spinal pathology of the upper thoracic spine through a partial manubriotomy. J Neurosurg Spine, 2011; 15: 467-471.
7. Brogna C, Thakur B, Fiengo L, Tsoti SM, Landi A, Anichini G, Vergani F, Malik I. Mini Transsternal Approach to the Anterior High Thoracic Spine (T1-T4 Vertebrae). Biomed Res Int. 2016: 4854217.

8. Gavriliu TS, Japie EM, Ghita RA, Hamei S, Dughila C, Tiripa IL, Elnayef T.Burnei's anterior transthoracic retropleural approach of the thoracic spine: a new operative technique in the treatment of spinal disorders. J Med Life, 2015; 8: 160-165.

9. Xiao ZM, Zhan XL, Gong DF, De Li S. Surgical management for upper thoracic spine tumors by a transmanubrium approach and a new space. Eur Spine J. 2007; 16: 439-444.

10. Maciejczak A, Radek A, Kowalewski J, Palewicz A . Anterior transsternal approach to the upper thoracic spine. Acta Chir Hung. 1991; 38: 83-86.

11. Seol HJ, Chung CK, Kim HJ. Surgical approach to anterior compression in the upper thoracic spine. J Neurosurg. 2002; 97: 337-342.

12. Takenaka S, Mukai Y, Hosono N, Fuji T . Major surgical treatment of osteoporotic vertebral fractures in the elderly: a comparison of anterior spinal fusion, anterior-posterior combined surgery and posterior closing wedge osteotomy. Asian Spine J. 2014; 8: 322330 .

13. Hodgson AR, Stock FE, Fang HS, Ong GB.Anterior spinal fusion. The operative approach and pathological findings in 412 patients with Pott's disease of the spine. Br J Surg. 1960; 48: 172-178.

14. Zhao Y, Wang Y, Xiao S, Zhang Y, Liu Z, Liu B. Transthoracic approach for the treatment of calcified giant herniated thoracic discs. Eur Spine J. 2013; 22: 2466-2473.

15. Boriani S, Bandiera S, Colangeli S, Ghermandi R, Gasbarrini A. En bloc resection of primary tumors of the thoracic spine: indications, planning, morbidity. Neurol Res. 2014; 36: 566-576.

16. Tangco AF, Rivera MT, Silao JV, Jr., Awitan AP, Jr. Approaches in anterior spinal fusion. Philipp J Surg Surg Spec. 1996; 21: 155-159.

17. Urschel HC, Jr. The transaxillary approach for treatment of thoracic outlet syndromes. Semin Thorac Cardiovasc Surg. 1996; 8: 214-220.

18. Crandell WB, Bosien WR .Transaxillary approach for upper thoracic sympathetic ganglionectomy. Ann Surg. 1995; 142: 28-31.

19. Becker RM, Munro DD. Transaxillary minithoracotomy: the optimal approach for certain pulmonary and mediastinal lesions. Ann Thorac Surg. 1976; 22: 254-259.

20. Krishnan KG, Pinzer T, Schackert G. The transaxillary approach in the treatment of thoracic outlet syndrome: a neurosurgical appraisal. Zentralbl Neurochir. 2005; 66: 180-189.

21. Brogna C, Thakur B, Fiengo L, Tsoti SM, Landi A, Anichini G, Vergani F, Malik I . Mini Transsternal 
Approach to the Anterior High Thoracic Spine (T1-T4

Vertebrae). Biomed Res Int. 2016: 4854217.

22. Falavigna A, Righesso O, Teles AR.Anterior approach to the cervicothoracic junction: proposed indication for manubriotomy based on preoperative computed tomography findings. J Neurosurg Spine, 2011; 15: 3847.

23. Crandell WB, Bosien WR .Transaxillary approach for upper thoracic sympathetic ganglionectomy. Ann Surg. 1995; 142: 28-31.

\section{Additional Information}

Disclosures: Authors report no conflict of interest.

Ethical Review Board Approval: The study was conformed to the ethical review board requirements.

Human Subjects: Consent was obtained by all patients/participants in this study.

Conflicts of Interest:

In compliance with the ICMJE uniform disclosure form, all authors declare the following:

Financial Relationships: All authors have declared that they have no financial relationships at present or within the previous three years with any organizations that might have an interest in the submitted work.

Other Relationships: All authors have declared that there are no other relationships or activities that could appear to have influenced the submitted work.

Address for Correspondence:

Dr. Fahmida Arab Mallah

Peoples University of Medical and Health Sciences for Women, Shaheed Benazirabad

Contact No. +923337061704

Email:fahmidamallah25@gmail.com

\begin{tabular}{|l|l|l|l|}
\hline \multicolumn{3}{|c|}{ AUTHORSHIP AND CONTRIBUTION DECLARATION } \\
\hline Sr.\# & Author's Full Name & Intellectual/Contribution to Paper in Terms of: \\
\hline 1. & Fahmida Arab Mallah & 1. Paper Writing. \\
\hline 2. & Abdul Razzaque Mari & 2. Proof Reading and Correction \\
\hline 3. & Muzamil Dilber & 3. Tables and Pictures. \\
\hline 4. & Shams Raza Brohi & 5. Literature Search \\
\hline 5. & Syed Aamir Shah & 6. Data Collection \\
\hline 6. & Muhammad Ali Jamali & 7. Proof Reading and Correction \\
\hline 7. & Hamid Akbar Shaikh &
\end{tabular}

Date of Submission: 15-01-2020

Date of Revision: 29-02-2020

Date of Online Publishing: 31-03-2020

Date of Print: 31-03-2020 